\title{
Cross-sectional and M-mode Echocardiographic Study on Ventricular Septal Defect
}

\author{
Norio Hıвi, M.D. and Tadashi Kambe, M.D.
}

\section{SUMMARY}

One hundred and eight patients with ventricular septal defect (VSD) including 20 operated patients were studied with real time cross-sectional echocardiography combined with M-mode echocardiography.

The subjects were divided into 3 groups according to the crosssectional echocardiographic findings. Group 1 included 34 patients in whom the defect area of interventricular septum (IVS) was demonstrated and they were diagnosed as VSD solely with this method. The majority of the patients in this group showed marked pulmonary hypertension and severe cardiac symptoms. Group 2 consisted of 13 patients who showed abruptly posterior movement of IVS toward the left ventricular cavity at early diastole and were suspected of VSD. Group 3 consisted of 41 patients with VSD showing normal cross-sectional echocardiograms without echo discontinuity of IVS. This group had a small defect of IVS with near normal pulmonary artery pressure.

The analysis of cross-sectional echocardiogram combined with M-mode echocardiogram and the data of other cardiac examinations revealed that group I showed a larger left-to-right shunt at the ventricular level, severer pulmonary hypertension and more marked heart enlargement than groups 2 and 3.

The patients with visualized defect of IVS had severe cardiac signs and symptoms and were indicated for the cardiac surgery.

In the postoperative patients, the patch echo was clearly recognized as a linear strong echo.

Real time cross-sectional echocardiography is available to visualize directly the defect of IVS in the majority of the patients with VSD and to estimate the condition of patients with this lesion.

\section{Additional Indexing Words :}

Ventricular septal defect Cross-sectional echocardiography Mechanical sector scanning M-mode echocardiography Real time observation Patch echo

$\mathrm{V}$ ENTRICULAR septal defect(VSD) is a very common congenital heart disease, and the detection of the size and location of the defect of IVS is quite important in terms of assessing cardiac operability. However, echo-

\footnotetext{
From the Third Department of Internal Medicine, School of Medicine, Nagoya University, Tsurumai-cho 65, Showa-ku, Nagoya 466, Japan.

Received for publication August 7, 1978.
} 
cardiographic recognition of VSD is rather difficult in the isolated lesion or associated with minor cardiac malformations. Till now, the diagnosis of VSD has been confirmed by heart catheterization and angiocardiography. ${ }^{1,2)}$

With regard to the M-mode echocardiogram of VSD, only a few studies have been reported. ${ }^{3)-6)}$ The magnitude of the left-to-right shunt at the ventricular level was estimated by the analysis of the size of the left atrium. More hyperkinetic movement of IVS was recognized in some patients and the left-sided heart chambers were enlarged in the patients with large VSD. But the visualization of VSD itself was extremely difficult with only M-mode echocardiography. M-mode scan echocardiogram in which the transducer was rotated from the aorta to the apex of the left ventricle occasionally demonstrated the discontinuity of IVS. But it was not constantly recognized.

In contrast, cross-sectional echocardiography has provided significant diagnostic information on VSD that is not available by M-mode echocardiography. ${ }^{7-9)}$ The purpose of this study is to visualize directly the defect of IVS and to describe the characteristic findings of VSD by real time crosssectional echocardiography combined with M-mode one.

\section{Materials and Methods}

This study includes 88 patients of VSD (49 males and 39 females : 8 months to 53 years of age) and 20 postoperative VSD patients (11 males and 9 females: 1 to 27 years of age) examined from July 1974 to Junc 1977 . Eighty-four patients underwent at least one cardiac catheterization. But in the remainder, the diagnosis was assessed on clinical data alone.

The cardiac diagnosis of the examined patients was shown in Table 1. Patients

Table I. Description of Cardiovascular Malformations Associated with VSD

\begin{tabular}{lc}
\multicolumn{1}{c}{ Malformations } & No. of Patients \\
\hline VSD isolated* & 66 \\
VSD associated with & $24^{* *}$ \\
Atrial septal defect & 2 \\
Patent ductus arteriosus & 7 \\
Two chambered right ventricle & 3 \\
Aneurysm of Valsalva sinus & 4 \\
Mitral insufficiency & 2 \\
Pulmonary insufficiency & 1 \\
Coarctation of aorta & 2 \\
Persistent left superior vena cava & 1 \\
Eisenmenger complex & 2
\end{tabular}

* Included in this group are VSDs coexisting with pulmonary stenosis and those which coexist with aortic regurgitation.

** Some patients had more than one associated malformation. 
with an associated pulmonary tract abnormality such as pulmonary stenosis, or aortic regurgitation were included in this study, along with isolated VSD. Patients with minor cardiac malformations whose prognosis would not be affected were also included. No patients with complex cardiopathies which had VSD (such as tetralogy of Fallot, transposition of the great arteries) were included. Twenty normal subjects were also examined with this method as control.

A Toshiba Model SSL-51H Sonolayergraph with mechanical sector scanning system was used. The details and usefullness of this system were reported previously. ${ }^{10)-13}$ The transducer was $10 \mathrm{~mm}$ in diameter, focused at $75 \mathrm{~mm}$, with a resonant frequency of $3 \mathrm{MHz}$, and it was used at a repetition rate of $3.6 \mathrm{KHz}$. The sector speed was 30 or 36 cross-sections per second and the sector angle was arbitrarily opened from $30^{\circ}$ to maximum of $90^{\circ}$, but the display angle of the oscilloscope screen was usually fixed at about $80^{\circ}$.

The patients were examined in the supine position. For acoustic coupling between the transducer and the chest surface, the so-called "proximity-immersed method" was employed. ${ }^{14)}$

Two methods were utilized to record the images of cross-sectional echocardiograms. (1) a Polaroid camera or an ordinary $35 \mathrm{~mm}$ camera was used at a shutter speed of $1 / 15 \mathrm{sec}$ or in synchrony with the QRS complex of the patient's electrocardiogram for stop motion images. (2) $8 \mathrm{~mm}$ movie camera was used at 15 frames/sec for the continuous recording of the heart movement.

In all of patients, cross-sectional echocardiograms were recorded along the long and short cardiac axes, as well as horizontal and sagittal planes of the chest. In the majority of the patients, 2 or 3 sections were analysed. In this report, the cross-sections of the long cardiac axis and sagittal plane of the chest were mainly used to readily obtain the characteristic features of VSD.

\section{Results}

1. Cross-sectional echocardiographic findings:

In normal subjects, no abnormalities were obtained in cross-sectional echocardiogram when the scanned sector was oriented parallel to the long cardiac axis and the sagittal plane of the chest, different from those in VSD. As shown in Fig. 1, the echo of the anterior mitral leaflet(AML) is demonstrated at the posterior region from a transducer position in the cross-section of the long cardiac axis(panel A). The anterior and posterior walls of aorta(AO) appear as parallel lines of echoes. Posterior to the AO lies the left atrium(LA). The interventricular septum(IVS) is represented as a thick band of echoes extending antero-caudally from the anterior wall of $\mathrm{AO}$ to the anterior wall of heart. The IVS is clearly recorded and shows no echo discontinuity. Anteriorly lies the oval cross section of the right ventricular outflow tract. The triangular outline of the left ventricle is located posterior to the IVS.

In the sagittal cross-section, the IVS runs from supero-posteriorly to infero-anteriorly without echo discontinuity in IVS(panel B). Anterior to the 

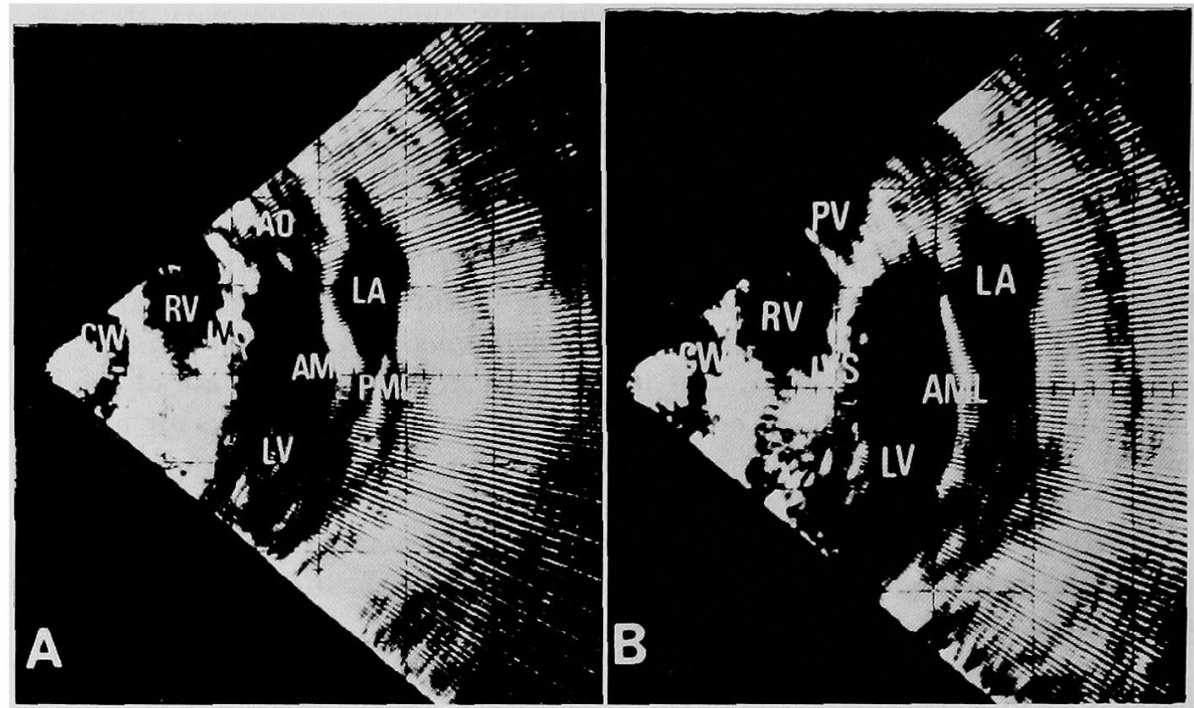

Fig. 1. Cross-sectional echocardiograms in normal subject. Panel A was recorded in the cross-section of the long cardiac axis and panel $\mathrm{B}$ in the cross-section of the sagittal plane of the chest. The interventricular septum (IVS) shows complete form as a thick band and echo discontinuity is not recognized both in 2 cross-sections. $\mathrm{GW}=$ chest wall, $\mathrm{RV}=$ right ventricle, IVS =interventricular septum $\mathrm{AO}=$ aorta, $\mathrm{AML}=$ anterior mitral leaflet, $\mathrm{PML}=$ posterior mitral leaflet, $\mathrm{LA}=$ left atrium, $\mathrm{LV}=$ left ventricle, $\mathrm{PV}=$ pulmonary valve.

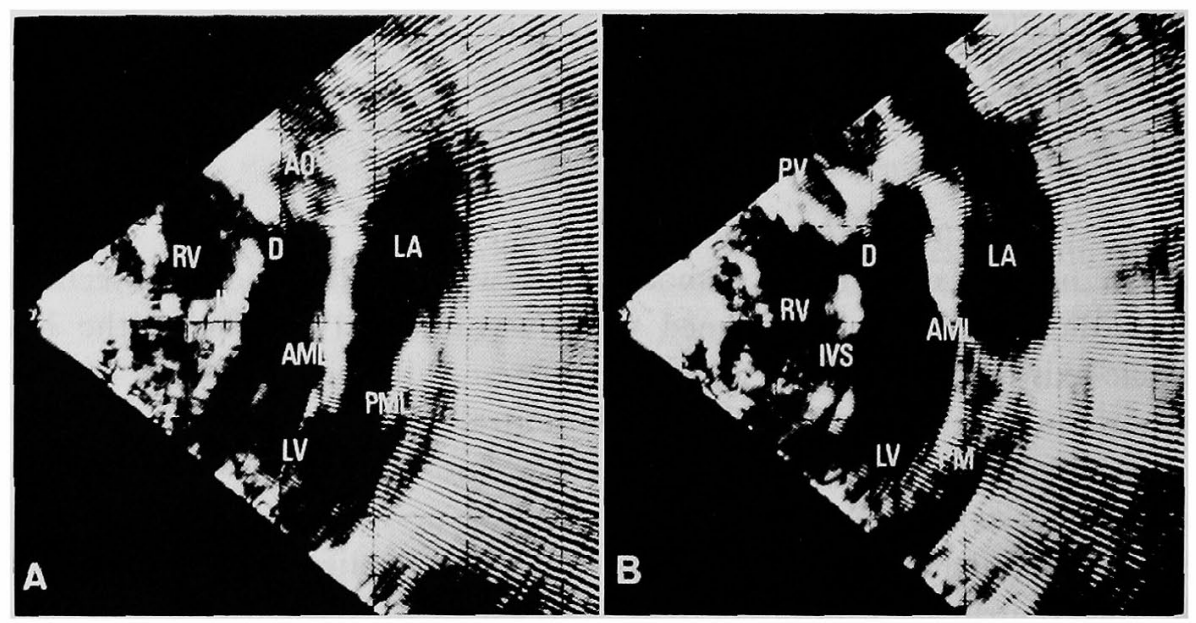

Fig. 2. Cross-sectional echocardiograms in a 1-year-old boy in group 1 . Panel A was taken in the cross-section along the long cardiac axis and panel $\mathrm{B}$ was recorded in the cross-section of the sagittal plane of the chest. The discontinuity of IVS (D) is clearly recognized both in 2 cross-sections. The diameter of discontinuity is larger in panel B than in panel A. The hyperkinetic movement of pulmonary valve is also demonstrated in panel B. RV= right ventricle, IVS = interventricular septum, $\mathrm{AO}=$ aorta, $\mathrm{D}=$ discontinuity of IVS, $\mathrm{AML}=$ anterior mitral leaflet, $\mathrm{PML}=$ posterior mitral leaflet, $\mathrm{LA}=$ left atrium, $L V=$ left ventricle, $P V=$ pulmonary valve. $\quad P M=$ pupillary muscle. 
upper portion of IVS, the pulmonary valve is recorded and the mitral valve is demonstrated on the opposite site. Each heart chamber is normal in size and the discontinuity of IVS is not recognized in the 2 cross-sectional echocardiograms.

The patients with VSD were divided into 3 groups according to the findings of IVS in cross-sectional echocardiograms in this study. Group 1 included 34 patients who showed the defect of IVS and were diagnosed as VSD only with this method. Group 2 consisted of 13 patients who showed abnormal posterior movement of IVS mainly at early diastole and were thought to have VSD. Group 3 was composed of 41 patients of VSD with normal crosssectional echocardiograms and no discontinuity of IVS.

Figure 2 shows the cross-sectional echocardiograms of a 1-year-old boy in group 1. In the cross-section of the long cardiac axis (panel A), the discontinuity of IVS was clearly recognized at the upper part of the IVS just below the aortic valve. The echo discontinuity was $8 \mathrm{~mm}$ in diameter. Other parts of the IVS showed no abnormalities and no additional echo discontinuity was demonstrated. The cavity of the left-sided heart was larger than that in normal subjects.

In addition, in the cross-section of the sagittal plane of the chest, the discontinuity of IVS was also demonstrated just below the pulmonary valve (panel B). This was more obviously recognized in this cross section and the discontinuity was $10 \mathrm{~mm}$ in diameter. The pulmonary valve was clearly recorded and showed hyperkinetic movement probably due to pulmonary hypertension. In this patient, heart catheterization revealed marked pulmonary hypertension, and the defect of IVS of $12 \mathrm{~mm}$ in diameter fell into Kirklin type II, just below the pulmonary valve at cardiac surgery.

Figure 3 was recorded in an 18-year-old female with Eisenmenger complex in group 1. Panel A is the cross-sectional echocardiogram and panel $\mathrm{B}$ is the M-mode scan echocardiogram. The discontinuity of IVS(D) was recognized and the faint echo trace was demonstrated both in cross-sectional and M-mode scan echocardiograms.

The B-mode echocardiograms of a 36-year-old housewife associated with mitral regurgitation in group 2 were shown in Fig. 4. Panel A was recorded in the cross-section of the long cardiac axis and panel $B$ was recorded in the cross-section parallel to the line $1 \mathrm{~cm}$ below the long cardiac axis. The enlarged left ventricle and atrium were demonstrated in the long cardiac axis. But the IVS appeared to be almost normal and the discontinuity of IVS was not recognized in panel A. B-mode echocardiogram in panel B revealed that the IVS moved posteriorly and abruptly toward the left ventricular cavity in early diastole (arrow), but the discontinuity of IVS was not constantly recognized. Thus 


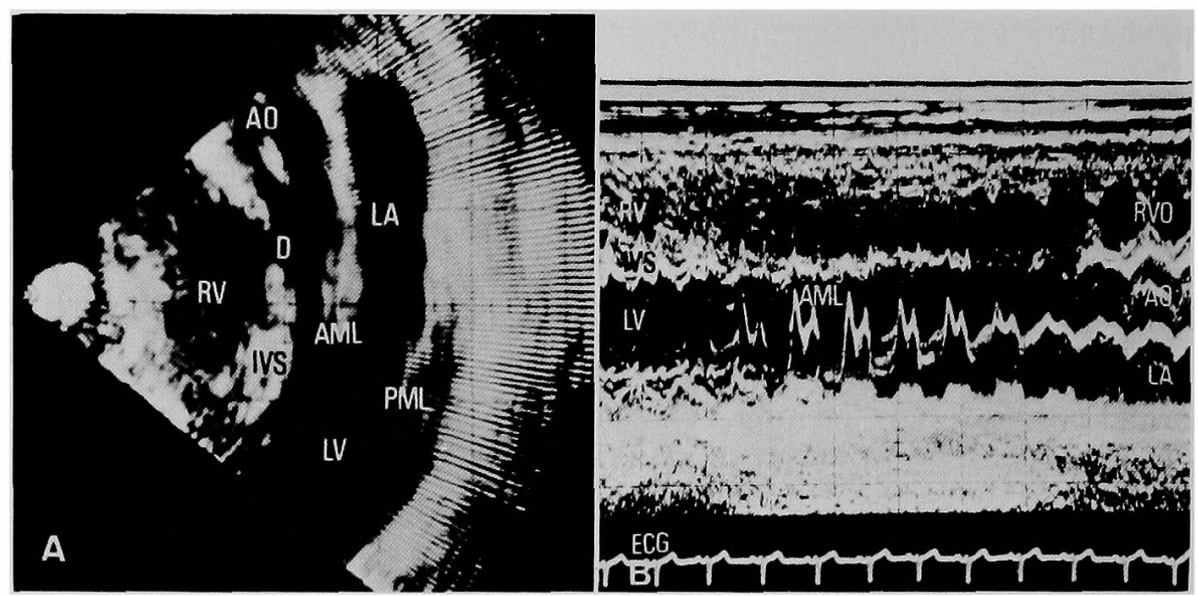

Fig. 3. Cross-sectional echocardiogram and M-mode scan echocardiogram recorded in an 18-year-old female with Eisenmenger complex in group 1. The discontinuity of IVS (D) is clearly demonstrated in panel A and the faint echo trace is also recognized at the upper part of IVS in M-mode scan echocardiogram. $\mathrm{RV}=$ right ventricle, $\mathrm{AO}=$ aorta, $\mathrm{D}=$ defect, IVS=interventricular septum, $\mathrm{AML}=$ anterior mitral leaflet, $\mathrm{PML}=$ posterior mitral leaflet, $\mathrm{LA}=$ left atrium, $\mathrm{LV}=$ left ventricle, $\mathrm{RVO}=$ right ventricular outflow tract, $\mathrm{ECG}=$ electrocardiogram.

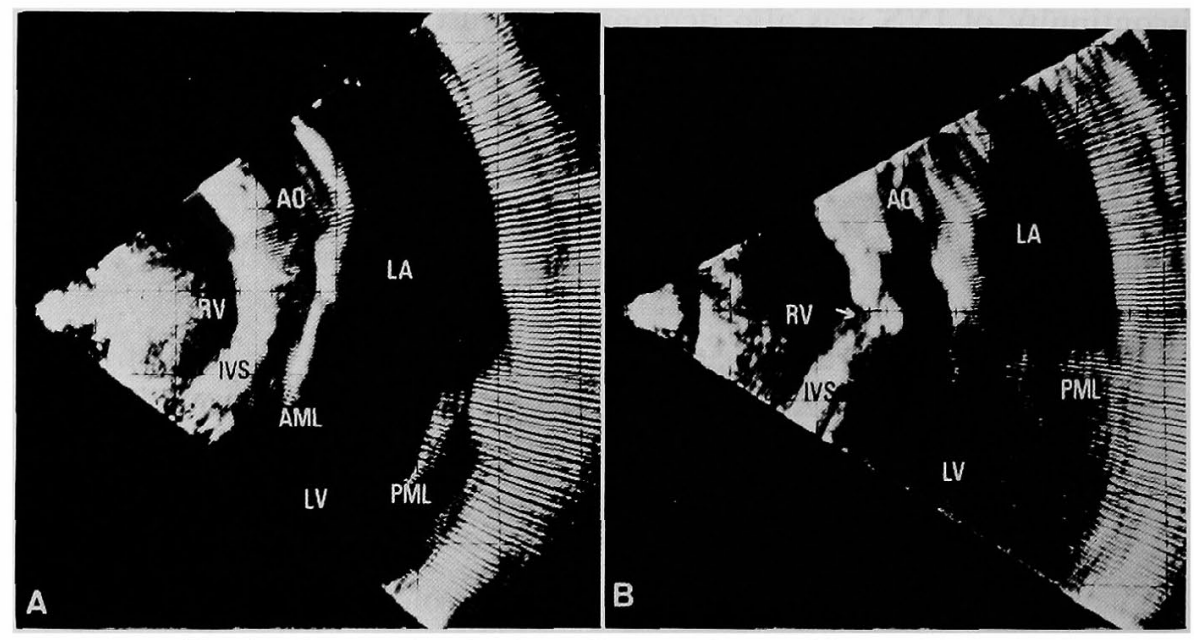

Fig. 4. Cross-sectional echocardiograms from a 36-year-old housewife with VSD associated with mitral regurgitation in group 2. Panel A was recorded in the cross-section of the long cardiac axis and B was taken in the crosssection parallel to the line $1 \mathrm{~cm}$ below the long cardiac axis. In the cross-section of the long cardiac axis, enlarged left atrium and ventricle are demonstrated, but the echo discontinuity of IVS is not shown, However, panel B shows the abruptly posterior movement of IVS $(\rightarrow) . \quad$ RV $=$ right ventricle, IVS =interventricular septum, $\mathrm{AO}=$ aorta, $\mathrm{AML}=$ anterior mitral leaflet, $\mathrm{PML}=$ posterior mitral leaflet, $\mathrm{LA}=$ left atrium, $\mathrm{LV}=$ left ventricle, arrow $(\rightarrow)=$ abnormal movement. 


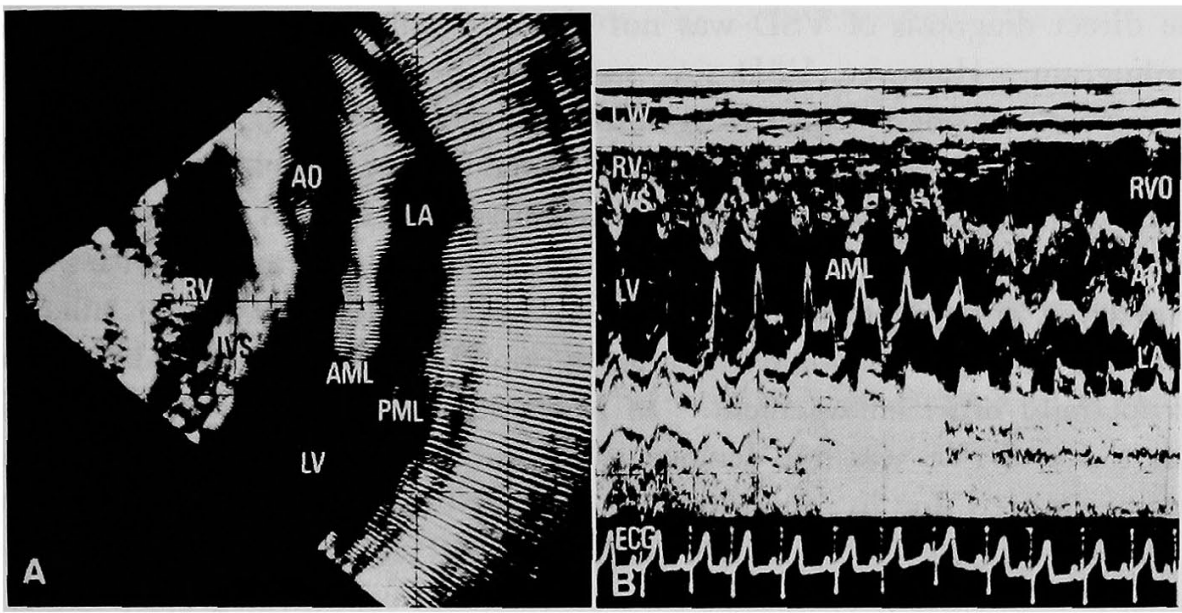

Fig. 5. Cross-sectional echocardiogram and M-mode scan echocardiogram in a 6-year-old boy in group 3. Both echocardiograms revea! no echo discontinuity of IVS. In M-mode scan echocardiogram, slight irregular movement of IVS due to respiration is demonstrated. RV=right ventricle, $\mathrm{AO}=$ aorta, $\mathrm{IVS}=$ interventricular septum, $\mathrm{AML}=$ anterior mitral leaflet, $\mathrm{PML}=$ posterior mitral leaflet, $\mathrm{LA}=$ left atrium, $\mathrm{LV}=$ left ventricle, $\mathrm{CW}=$ chest wall, $\mathrm{RVO}=$ right ventricular outflow tract, $\mathrm{ECG}=$ electrocardiogram.
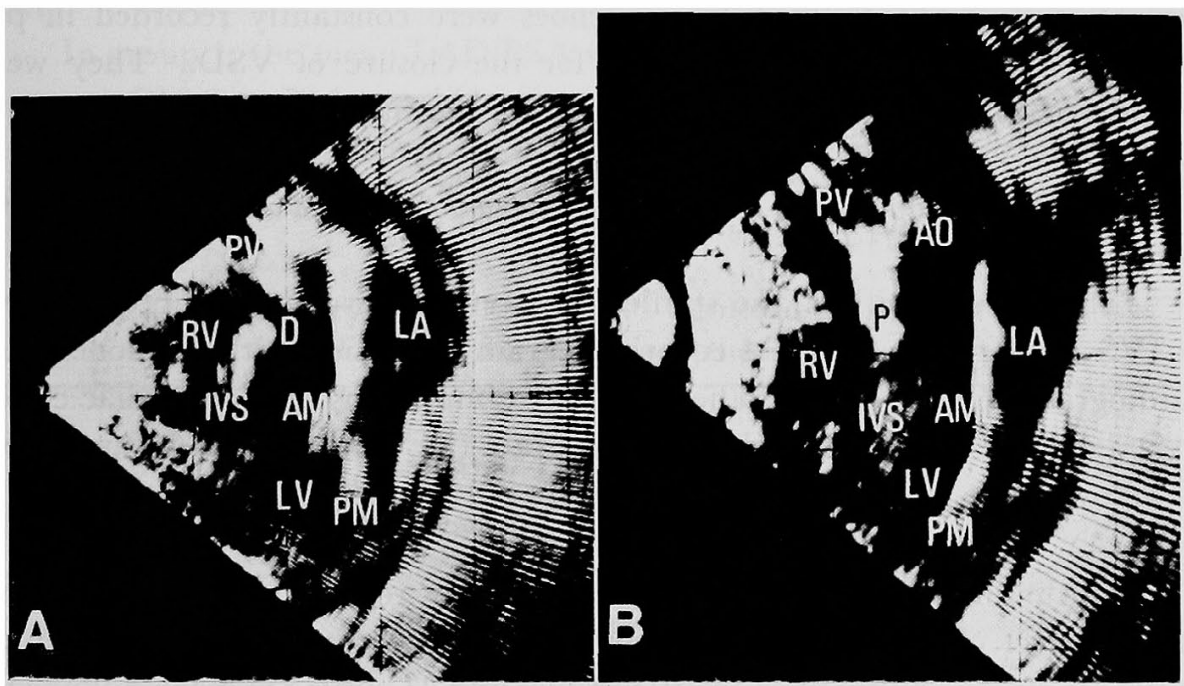

Fig. 6. Cross-sectional echocardiograms in a 1-year-old boy with VSD. Panel A shows preoperative image and panel $\mathrm{B}$ was recorded after cardiac repair of VSD. The strong linear echo $(\mathrm{P})$ is demonstrated at the upper part of IVS which preoperatively shows the discontinuity of IVS. RV=right ventricle. $\mathrm{PV}=$ pulmonary valve. $\mathrm{IVS}=$ interventricular septum. $\mathrm{D}=$ defect. $\mathrm{AML}=$ anterior mitral leaflet, $\mathrm{LA}=$ left atrium, $\mathrm{LV}=$ left ventricle, $\mathrm{PM}=$ papillary muscle, $\mathrm{P}=$ patch, $\mathrm{AO}=$ aorta. 
the direct diagnosis of VSD was not obtained only by cross-sectional echocardiogram. However, VSD was suspected because this abnormal septal movement was not recognized in normal subjects.

Figure 5 is the cross-sectional and M-mode scan echocardiograms from a 6-year-old boy in group 3 with normal movement of IVS showing no echo discontinuity. The IVS was clearly demonstrated antero-caudally with a thick echo band with continuous trace. The heart cavity was not so enlarged. Namely, this cross-sectional echocardiogram showed almost normal pattern except mild heart enlargement. In M-mode scan echocardiogram, the discontinuity of IVS was not demonstrated, but the slight irregular movement was recognized due to respiration.

The diagnosis of VSD was made or suspected in the half of the VSD patients with cardiac symptoms by cross-sectional echocardiography and it is important in terms of possible cardiac surgery and for the prognosis especially in childhood.

Figure 6 was recorded from a 1-year-old boy with VSD. Preoperatively (panel A), this patient showed an obvious echo discontinuity in IVS of $1.0 \mathrm{~cm}$ in diameter just below the pulmonary valve in the sagittal cross-section of the chest. But postoperatively(panel B), a strong linear echo from teflon patch(P) was recognized at the upper part of IVS, which preoperatively showed an echo discontinuity. These strong linear echoes were constantly recorded in patients in whom teflon patch was used for the closure of VSD. They were considered to emanate from patches used for cardiac surgery.

\section{Relationship between cross-sectional echocardiogram and other cardiac examina-} tions:

The correlation was also studied between the visualization of the defect of IVS by the cross-sectional echocardiogram combined with M-mode echocardiogram and the data of other cardiac examinations such as cardiac catheterization, chest X-ray and electrocardiogram (ECG). The results are shown as follows:

(A) Pulmonary artery pressure

The pulmonary artery pressure was closely related to the visualization of the defect of IVS. In marked pulmonary hypertension (higher than 50 $\mathrm{mmHg}$ in systolic pulmonary artery pressure and $25 \mathrm{mmHg}$ in mean pulmonary artery pressure), 26 of the 32 patients showed the echo discontinuity in the IVS $(81.3 \%$ ). In mild pulmonary hypertension(higher than $30 \mathrm{mmHg}$ in systolic pulmonary artery pressure and $20 \mathrm{mmHg}$ in mean pulmonary artery pressure), 4 of the 10 paticnts revealed the echo discontinuity of IVS $(40 \%)$, but the defect of IVS was visualized in only 4 of the 24 pulmonary normotensives 
$(16.8 \%)$. In the remaining 22 patients, the catheterization data were not analyzed.

In group 1, 26 patients showed marked pulmonary hypertension(76.5\%). But no specific findings of pulmonary artery pressure were noted in group 2, and the majority of group 3 showed normal pulmonary artery pressure.

(B) Pulmonary to systemic flow ratio( $\left.Q_{p} / Q_{s}\right)$

The magnitude of the left-to-right shunt volume was expressed as an index of Qp/Qs. Larger $Q p / Q$ s at ventricular level was recognized in group 1 (mean $\pm \mathrm{SE}=2.3 \pm 0.2$, with a range of 1.3 to 5.7$)$. Group $2(1.4 \pm 0.1$, with a range of 1.1 to 1.8$)$ and group $3(1.6 \pm 0.1$, with a range of 1.1 to 2.0$)$ revealed smaller Qp/Qs ratio than group $1(1: 3, \mathrm{p}<0.01)$.

(C) Cardio-thoracic ratio(CTR)

Heart size in chest $\mathrm{X}$-ray was shown as a cardio-thoracic ratio(CTR). In group 1 , it was $59.6 \pm 1.0 \%$ (mean $\pm \mathrm{SE}$ ) with a range of 48 to $68 \%$, group 2 indicated it was $56.7 \pm 2.1 \%$ with a range of 51 to $63 \%$ and it was $50.6 \pm 1.2 \%$ with a range of 44 to $68 \%$ in group 3 . Group 1 and 2 had larger CTRs than group $3(1: 3, \mathrm{p}<0.001,2: 3, \mathrm{p}<0.05)$.

In ECG, the patients in group 1 tended to show heart enlargement, but the majority of the patients in group 3 showed normal ECG. BSA)

(D) Left atrial dimension corrected for the body surface area (LAD/

In group 1, the mean LAD/BSA was $43.0 \pm 2.7 \mathrm{~mm} / \mathrm{M}^{2}($ mean $\pm \mathrm{SE})$ with a range of 16.0 to $79.5 \mathrm{~mm} / \mathrm{M}^{2}$. It was larger than that in group $2(37.1 \pm$ $5.1 \mathrm{~mm} / \mathrm{M}^{2}$ with a range of 16.0 to $\left.81.0 \mathrm{~mm} / \mathrm{M}^{2}\right)$ and group $3(26.5 \pm 1.3$ $\mathrm{mm} / \mathrm{M}^{2}$ with a range of 15.0 to $61.0 \mathrm{~mm} / \mathrm{M}^{2}$ ). Group 1 had an obviously

Table II. Summary of the Findings of Clinical and Echocardiographic Examination in 3 Groups of VSD

\begin{tabular}{|c|c|c|c|c|c|c|c|c|c|c|}
\hline & & \multirow[b]{2}{*}{ Qp/Qs } & \multicolumn{7}{|c|}{ Echocardiographic Features } & \multirow[b]{2}{*}{$\begin{array}{c}\text { Diameter } \\
\text { of Defect } \\
\text { (mm) }\end{array}$} \\
\hline & & & $\begin{array}{l}\operatorname{CTR} \\
(\%)\end{array}$ & $\begin{array}{c}\text { AML } \\
\text { DDP } \\
(\mathrm{mm} / \mathrm{s})\end{array}$ & $\mathrm{A} / \mathrm{E}$ & EF & $\begin{array}{c}\mathrm{AO} / \mathrm{BSA} \\
\left(\mathrm{mm} / \mathrm{M}^{2}\right)\end{array}$ & $\begin{array}{c}\mathrm{LA} / \mathrm{BSA} \\
\left(\mathrm{mm} / \mathrm{M}^{2}\right)\end{array}$ & $\mathrm{AO} / \mathrm{LA}$ & \\
\hline Group 1 & (mean) & 2.3 & 59.6 & 110.1 & 0.58 & 0.73 & 37.9 & 43.0 & 0.85 & 12.9 \\
\hline$(n=34)$ & $(\mathrm{SE})$ & 0.2 & 1.0 & 3.9 & 0.02 & 0.01 & 1.8 & 2.7 & 0.04 & 1.4 \\
\hline Group 2 & (mean) & 1.4 & 56.7 & 114.9 & 0.56 & 0.78 & 26.9 & 37.1 & 0.83 & 8.5 \\
\hline$(\mathrm{n}=13)$ & $(\mathrm{SE})$ & 0,1 & 2.1 & 7.6 & 0.03 & 0.02 & 3.5 & 5.1 & 0.04 & 1.5 \\
\hline Group 3 & (mean) & 1.6 & 50.6 & 125.9 & 0.57 & 0.73 & 24.7 & 26.5 & 0.96 & 4.7 \\
\hline$(\mathrm{n}=41)$ & (SE) & 0.1 & 1.2 & 5.0 & 0.02 & 0.02 & 0.9 & 1.3 & 0.03 & 0.3 \\
\hline
\end{tabular}

$\mathrm{QP} / \mathrm{Qs}=$ pulmonary to systemic flow ratio, $\mathrm{CTP}=$ cardio-thoracic ratio, $\mathrm{AML}=$ anterior mitral leaflet, $\mathrm{DDR}=$ diastolic descent rate, $\mathrm{A} / \mathrm{E}=\mathrm{A}$ amplitude/E amplitude of $\mathrm{AML}, \mathrm{EF}=\mathrm{ejection}$ fraction, $\mathrm{AO}=$ aorta, $\mathrm{LA}=$ left atrium, $\mathrm{BSA}=$ body surface area. 
larger left atrium and group 2 had also an enlarged left atrium. (1:3, p< $0.001,2: 3, \mathrm{p}<0.01)$.

(E) Aortic dimension corrected for the body surface area(AO/BSA)

The mean AO/BSA in group 1 was $37.2 \pm 1.8 \mathrm{~mm} / \mathrm{M}^{2}($ mean $\pm \mathrm{SE}$ ) with a range of 19.0 to $58.0 \mathrm{~mm} / \mathrm{M}^{2}$. In group 2, it was $26.9 \pm 3.8 \mathrm{~mm} / \mathrm{M}^{2}$ with a range of 13.0 to $55.0 \mathrm{~mm} / \mathrm{M}^{2}$, and it was $24.7 \pm 0.9 \mathrm{~mm} / \mathrm{M}^{2}$ with a range of 15.0 to $35.0 \mathrm{~mm} / \mathrm{M}^{2}$ in group 3 , as shown in Table II. Group 1 showed wider aorta $(1: 2, \mathrm{p}<0.05,1: 3, \mathrm{p}<0.001)$.

As a result, the Qp/Qs, CTR, LAD/BSA, and AO/BSA were significantly larger in group 1 than in group 3. The DDR of $\mathrm{AML}, \mathrm{A} / \mathrm{E}$ ratio, ejection fraction(EF) were not significantly different among these 3 groups, as shown in Table II.

\section{Size of VSD:}

Thirty-four patients in group 1 clearly showed the defect of IVS as an echo discontinuity. The type of VSD mostly fell into Kirklin type I, II, or mixed type of I and II. ${ }^{15)}$ The size of the echo discontinuity of IVS in crosssectional echocardiogram ranged from 5 to $20 \mathrm{~mm}$ in diameter with mean value of $10.5 \pm 1.2 \mathrm{~mm}$. At cardiac surgery, these patients had a defect of IVS from 8 to $30 \mathrm{~mm}$ in diameter with mean value of $12.9 \pm 1.4 \mathrm{~mm}$. Group 2 had a defect of IVS from 7 to $10 \mathrm{~mm}$ in diameter with mean value of $8.5 \pm$ $1.5 \mathrm{~mm}$ at cardiac surgery. And groups 3 showed VSD diameter of which was 4 to $6 \mathrm{~mm}$ with mean value of $4.7 \pm 0.3 \mathrm{~mm}$ at cardiac operation, although the defect of IVS was not directly visualized by cross-sectional echocardiogram in this group. The size of the defect in B-mode echocardiogram was slightly smaller than that at cardiac surgery.

\section{Discussion}

Recently, echocardiography has come into clinical use in congenital heart disease. ${ }^{16)-25)}$ Until now, however, the characteristic findings of VSD are generally not obtained with M-mode technique, although the discontinuity of IVS was occasionally demonstrated in extremely large VSD, and the direct visualization of the defect of IVS has been difficult.

In contrast, real time cross-sectional echocardiography enabled to visualize the whole IVS from the apex of the left ventricle to the junction of the anterior wall of aorta.

In this study, it was possible to watch the defect of IVS as an echo discontinuity with real time B-mode echocardiography. The IVS defect was clearly recognized in 34 patients. The size of the discontinuity displayed on 
the B-mode echocardiogram was slightly smaller than the actual size of defect at cardiac surgery. It may be due to the limited resolusion of the transducer or poor gain setting. It may also be ascribed to the spacial gap between the cross-sectional plane and the position of the defect.

Group 1 accounted for $39 \%$ of all patients, group 2 formed $15 \%$ of them, and group 3 made up 46\%. The patients with VSD underwent echocardiographic examination were limited to those who were referred to the Nagoya University Hospital for a thorough cardiac examination and underwent cardiac catheterization combined with angiocardiography and/or cardiac surgery. But the percentage of visualization of VSD is thought to be slightly low, since the patients with complex cardiac malformations having large VSD were excluded from this study. Although it is still difficult to visualize small VSD, real time cross-sectional echocardiography provided direct diagnostic findings of VSD in about half of the patients. And the visualization of the defect of IVS is thought to be a most characteristic feature of this lesion.

Moreover, our classification of VSD into 3 groups according to the crosssectional images is considered to be clinically useful, since the patients in group 1 had severe cardiac symptoms with higher pulmonary artery pressure and more enlarged heart chambers. Hence, they should undergo surgical intervention as early as possible.

A majority of 13 patients in group 2 showed abnormal posterior movement of IVS, though the clear discontinuity of IVS was not recognized in B-mode echocardiogram. A certain part of IVS abruptly moved posteriorly at early diastole, but the abnormal movement was not demonstrated throughout the cardiac cycle. It was probably attributable to its location difficult to be detected even by B-mode echocardiography. In the patients of VSD with aneurysm of the Valsalva sinus, the abnormal movement was recorded in IVS just below the aortic valve. Its movement was slightly different from the majority of the patients in this group. The abnormal movement suggested the presence of VSD since these abnormal movement was not recognizedin normal subjects and patients without this lesion.

Group 3 showed almost normal cross-sectional echocardiograms, in which the discontinuity of IVS was not recognized and the IVS showed normal movement. This group was further divided into 2 sub-groups by the size of the heart cavity and the movement of the IVS and posterior wall of the left ventricle(LVPW) in cross-sectional echocardiogram. One of them had mildly enlarged left-sided heart cavities and hyperkinetic movement of heart, and the other was both normal in heart size and movement. This group showed normal pulmonary artery pressure and developed no severe cardiac symptoms. 
The cardiac operation is not always necessary in group 3, although the patients with enlarged heart cavities and hyperkinetic movement should probably undergo surgical intervention.

In postoperative patients, the patch echo was detectable in the majority of the patients in whom teflon patch was used for the closure of VSD. It was demonstrated as a strong, linear echo at the region where there was the echo discontinuity prior to operation. A large echo interruption was occasionally noted by cross-sectional technique at the margin of patch, suggesting blood leakage. ${ }^{26)}$ However, a smaller one could not be recognized only by this method.

An analysis of the findings of other cardiac examinations revealed heart enlargement in chest X-ray, EGG and M-mode echocardiogram, and pulmonary hypertension in cardiac catheterization in group 1 . On the other hand, these data were within normal limits in group 3. Group 2 showed no specific findings. More characteristic findings were recognized in group 1 than in group 3.

Finally, real time cross-sectional echocardiography provided direct visualization of VSD in a higher percentage of patients with VSD and it is thought to be a useful tool for the diagnosis of VSD and evaluation of prc- and postoperative cardiac condition of patients with this lesion.

\section{ACKNowledgements}

The authors express deep gratitude to Prof. N. Sakamcto for his encouragement and guidance. The authors are also grateful to Prof. Y. Iyomasa, Dr. J. Akune, and Dr. Y. Hojs for their referral of patients. Thanks are also extended to Dr. K. Nishimura and Dr. Y. Fukui.

\section{REFERENCES}

1. Tatsuno K, Ando M, Takao A, Hatsune K, Konno S: Diagnostic importance of aortography in conal ventricular septal defect. Am Heart J 89: 171, 1975

2. Baron $M G$, Wolf BS, Steinfeld L, Gordon AJ: Left ventricular angiocardiography in the study of ventricular septal defects. Radiology 81: 223, 1973

3. Bloom KR, Rodrigues L, Swan EM: Echocardiographic evaluation of left-to-right shunt in ventricular septal defect and persistent ductus arteriosus. Brit Heart J 39: 260, 1977

4. Sahn DJ, Vaucher Y, Williams DE, Allen HD, Goldberg SJ, Friedman WF: Echocardiographic detection of large left to right shunts and cardiomyopathies in infants and children. Am J Cardiol 38: 73, 1976

5. Graham TPJr, Atwood GF, Boucek RJ Jr, Cordell D, Boerth RC: Right ventricular volume characteristics in ventricular septal defect. Circulation 54: 800, 1976

6. Lewis $\mathrm{AB}$, Takahashi $\mathrm{M}$ : Echocardiographic assessment of left-to-right shunt volume in children with ventricular septal defect. Circulation 54: 78, 1976

7. King DL, Steeg CN, Ellis K: Visualization of ventricular septal defects by cardiac ultrasono- 
graphy. Circulation 48: 1215, 1973

8. Nagata S, Matsumoto M, Beppu S, Tamai M, Nakano S, Matsuo H, Kawashima Y, Sakakibara $\mathrm{H}$, Nimura $\mathrm{Y}, \mathrm{Abe} \mathrm{H}$ : Ultrasonographic features of high ventricular septal defect and overriding of the aorta in tetralogy of Fallot studied with ultrasonocardiotomography and conventional echocardiography. Heart 6: 1680, 1974 (in Japanese)

9, Hibi N, Kato T, Fukui Y, Arakawa T, Nishimura K, Tatematsu H, Miwa A, Tada H, Kambe $\mathrm{T}$, Sakamoto N: Ultrasono-cardiotomographic study on tetralogy of Fallot by means of high speed mechanical sector scanning system. in Ultrasound in Med 3A, ed by White D, Broun RE, Plenum Publishing Corporation, New York, p 149, 1977

10. Takemura $Y$, Nakagawa K, Satoh S, Jingu M, Nishimura K, Hibi N, Tada H, Kambe T: High speed ultrasono-cardiotomography by mechanical scanning. Jap J Med Ultrasonics 1: 24,1974 (in Japanese)

11. Nishimura K, Hibi N, Kambe T, Sakamoto N, Takemura Y, Nakagawa K, Satoh S: High speed ultrasono-cardiotomography. Respir and Circulat 23: 925, 1975 (in Japanese)

12. Nishimura K, Hibi N, Kato T, Fukui Y, Arakawa T, Tatematsu H, Miwa A, Tada H, Kambe T, Nakagawa K, Takemura Y: Real time observation of cardiac movement and structures in congenital and acquired heart diseases employing high speed ultrasono-cardiotomography. Am Heart J 92: 340, 1976

13. Kambe T, Nishimura K, Hibi N, Sakakibara T, Kato T, Fukui Y, Arakawa T, Tatematsu H, Miwa A, Sakamoto N: Clinical application of high speed B-mode echocardiography. J Clin Ultrasound 5: 202, 1977

14, Ebina T, Oka S, Tanaka M, Kosaka S, Terasawa Y, Unno K, Kikuchi Y, Uchida R: The ultrasono-tomography for the heart and great vessels in living human subjects by means of ultrasonic reflection technique. Jap Heart J 8: 331, 1967

15. Kirklin JW, Harshbarger HG, Donald DE, Edwards JE: Surgical correction of ventricular septal defect; Anatomical and technical considerations. J Thoracic Surg 33 : 45, 1957

16. French JW, Popp R: Variability of echocardiographic discontinuity in double outlet right ventricle and truncus arteriosus. Circulation 51: 848, 1975

17. Meyer RA: Pediatric Echocardiography, Lea \& Febiger, Philadelphia, 1977

18. Williams RG, Tucker CR: Echocardiographic Diagnosis of Congenital Heart Disease, Little, Brown \& Co, Boston, 1977

19. Murphy KF, Kotler MN, Reichek N, Perloff JK: Ultrasound in the diagnosis of congenital heart disease. Am Heart J 89: 638, 1975

20. Morris DC, Felner JM, Schlant RC, Franch RH: Echocardiographic diagnosis of tetralogy of Fallot. Am J Cardiol 36: 908, 1975

$x 1$. Chung KJ, Nanda NG, Manning JA, Gramiak R: Echocardiographic findings in tetralogy of Fallot. Am J Cardiol 31: 126, 1973

22. Meyer RA, Shwartz DC, Covitz W, Kaplan S: Echocardiographic assessment of cardiac malposition. Am J Cardiol 33: 896, 1974

23. Solinger R, Elbl F, Minhas K: Echocardiography in congenital heart disease. Lancet 2: 1093,1971

24. Story WE, Felner JM, Schlant RG: Echocardiographic criteria for the diagnosis of mitralsemilunar valve continuity. Am Heart J 93: 575, 1977

25. Goldberg SJ, Allen HD, Sahn DJ: Pediatric and Adolescent Echocardiography. Year Book Medical Publishers, Chicago, 1975

26. Wilson RL, Shaub MS, Young G: The echocardiographic appearance of a partially disturbed ventricular septal repair. A case report. J Clin Ultrasound 4: 41, 1976 